\title{
EVALUATION OF THE MARGINAL INTEGRITY OF ALL-CERAMIC CROWNS FABRICATED WITH DIGITAL AND CONVENTIONAL IMPRESSION TECHNIQUES
}

\author{
Mohamed Mohey Eldin Mohamed*
}

\begin{abstract}
Aim : The purpose of this in vitro study was to compare the marginal gap discrepancy of lithium disilicate single crown fabricated with computer-aided design and computer-aided manufacturing (CAD/CAM) technology by using both conventional and digital impression techniques

Materials \& Methods: Lithium disilicate crowns were fabricated to fit on metal die either by digital impressions with Cerec 3D omnicam, followed by milling from IPS e.max CAD and conventional impression followed by fabrication of IPS e.max Press by using the lost-wax and heat-pressing techniques. Each crown was fixed to metal die and the marginal gap was measured for each specimen at 3 points under magnification with a stereomicroscope. Data were statistically analyzed by $\mathrm{T}$ test.
\end{abstract}

Results: The all ceramic specimens fabricated by digital image had a mean marginal adaptation width $79.9 \mu \mathrm{m}$ buccally and $77.1 \mu \mathrm{m}$ lingually, and the all ceramic specimens fabricated by conventional impression had a mean marginal adaptation width $84.6 \mu \mathrm{m}$ buccally and $84.4 \mu \mathrm{m}$ lingually with a significant difference.

CONCLUSION: Within the limitations of this study, all-ceramic crowns produced by CAD/ CAM system had external marginal adaptation accuracy better than all-ceramic crowns produced by dental laboratory with statistical significant difference

KEYWORDS: CAD/CAM, Dental laboratory, All-Ceramic crowns, external Marginal adaptation

\section{INTRODUCTION}

The goal of any dental clinician and manufacturer throughout the history of dentistry is to achieve an esthetically and functionally ideal restoration. ${ }^{(1)}$ The success of a dental restoration is determined by many factors as, esthetic value, resistance to fracture, and marginal adaptation. ${ }^{(2)}$
The use of all ceramic prosthesis in restorative treatments has become popular, many of these restorations can be fabricated by both traditional laboratory methods and CAD/CAM machines. ${ }^{(3,4)}$ The traditional methods of ceramic fabrication have been described to be time-consuming, technique sensitive and unpredictable due to the many

* Lecturer of Fixed Prosthodontics Delta University for Science and Technology 
variables, on the other hand CAD/CAM is a good alternative for both dentist and the laboratory.

Dental CAD/CAM technology is gaining popularity because of their benefits in terms of manufacturing time, material saving, standardization of the fabrication process, and predictability of the restorations. The new technologies offers similar or better results compared with conventional methods. ${ }^{(5)}$

CAD/CAM system can be used in conjunction with either laboratory or chairside manufacturing ${ }^{(6)}$. It offers the benefit of intraoral data acquisition with "optical impressions" (7) which can help reduce errors associated with conventional impression techniques, consequently it eliminates the need for the traditional impression taking, model-pouring, laboratory-shipping steps of fabricating crowns. Optical imaging of the dentition therefore can replace the use of conventional impression materials. ${ }^{(8)}$

The first commercially available digital intraoral impression system was used in 1987 and is known as the CEREC 1 system (Sirona Dental, Inc) Since then, several digital intraoral impression devices have been developed. ${ }^{(9)}$ Other than CEREC, the Lava chairside oral scanner (COS), iTero (3shape), E4D (Planmeca/E4D Technologies), and Trios (Custom Automated Prosthetics) systems are some of the available intraoral digital impression units currently used in the dental field. ${ }^{(10)}$

The incorporation of this technology has not only brought a new range of manufacturing methods and material options but also enhance restorations fit, quality, accuracy, short and long-term prognosis. ${ }^{(10)}$

Poor marginal fit has been associated with marginal discoloration, dissolution of cement, microleakage, increased plaque retention, and secondary decay. ${ }^{(11,12)}$

The purpose of the study was to compare the in vitro marginal adaptation of all-ceramic crowns produced by the optical imaging technique with the marginal adaptation of all-ceramic crowns produced by the conventional impression technique.
The hypothesis was that the marginal adaptation of all ceramic restorations are not affected by impression techniques

\section{MATERIALS \& METHODS}

A total number of twenty Maxillary First molar were prepared for a complete-coverage crown with the aid of a Isoparallelometers (Cruise 440). The preparation had a 90-degree shoulder with a rounded axio-gingival internal line angle. The preparation had a well-defined 360 circumferential shoulder gingival margin, of $1 \mathrm{~mm}$ width. The height of the preparation was about $7 \mathrm{~mm}$, with a convergence angle of 10 degrees.

\section{Metal die Specimens preparation}

A silicone impression was made of the prepared tooth to create a mold, and an autopolymerizing acrylic resin was poured into the impression to form a pattern that was used to create the metal die. The acrylic pattern was invested, subjected to the burnout process, and cast with a base metal alloy (Wiron 99, BEGO Bremer Goldschlägerei Wilh. Herbst GmbH \& Co. KG Germany ). ${ }^{(12)}$

\section{Grouping of the Specimens:}

The fabricated specimens were divided into two main groups $\mathrm{A}$ and $\mathrm{B}$ of 10 specimens each.

The group (A) was made of 10 , digital image to fabricate IPS e-max CAD CAM crowns specimens.

The group (B) was made of 10 , conventional technique to fabricate IPS e-max press crowns specimens.

\section{Fabrication of All-ceramic Crowns (Digital im- pression technique)}

Each metal tooth was placed in a full-denture typodont and scanned with Omnicam handheld according to the Cerec software's specifications. The crown margins were marked manually on the finish lines of the preparations. Spacer was set at 
$80 \mu \mathrm{m}$ away from the marginal by a $1-\mathrm{mm}$. The $3 \mathrm{D}$ crown design was calculated and generated from the database's software based on the images captured during a scanning procedure. Additionally, any adjustments made to the design within the software were noted to ensure consistency.

The complete crown design data was transmitted wirelessly to the milling unit which was loaded with IPS e.max CAD LT A1 all-ceramic block (Ivoclar vivadent AG Benderestrasse 2 FL-9494 Schaan Liechtenstein). ${ }^{(12)}$

\section{Fabrication of All-ceramic Crowns (Convention- al impression technique)}

The metal die was placed in full-denture typodont. A total of ten impressions were taken utilizing putty and wash impression techniques with light and putty consistency VPS (virtual) impression material (Ivoclar vivadent AG Benderestrasse 2 FL9494 Schaan) Liechtenstein).

The impressions were poured in Type IV dental stone two layers of die spacer was applied to the stone dies. The layers were applied uniformly with a brush, starting $1 \mathrm{~mm}$ short of the finish lines of the preparations. An anatomic contour wax was created for each master die and invested with finegrained phosphate-bonded investment material (IPS PressVEST Speed).

The pressing process was completed according to the manufacturer's instructions. (Programat EP 5000 press furnaces). IPS e.max Press lithium disilicate ingots (Ivoclar IPS e.max Press Low Translucency ingots) were used to fabricate the crowns.

\section{Crown Cementation and Analysis}

The crowns were cemented using Multilink Automix (Ivoclar Vivadent) according to the manufacture instructions under constant static weight of $2 \mathrm{~kg}$. A scaler was used to remove the excess of the remaining cement after 2 seconds. Afterwards, it was cured for 40 seconds using a light curing (LED) unit (Ivoclar Vivadent.
Benderestrasse 29494 Schann, Liechtenstein, Switzerland).All samples were then stored in distilled water for 24 hours at $37^{\circ} \mathrm{C}$ before analysis under stereo microscope with $50 \mathrm{X}$ magnification on three different points per buccal and lingual sides. ${ }^{(13)}$

The results were recorded, tabulated, and statistically analyzed.

\section{RESULTS}

\section{Statistical analysis:}

The Data was collected and entered into the personal computer. Statistical analysis was done using Statistical Package for Social Sciences (SPSS/ version 20) software.

Arthematic mean, standard deviation, for numerical data t-test (paired and unpaired) was used to compare two groups. The level of significant was 0.05 .

The all ceramic specimens fabricated by digital image had a mean marginal adaptation width 79.9 $\mu \mathrm{m}$ buccally and $77.1 \mu \mathrm{m}$ lingually. Table (1)

On the other hand the all ceramic specimens fabricated by conventional impression had a mean marginal adaptation width $84.6 \mu \mathrm{m}$ buccally and $84.4 \mu \mathrm{m}$ lingually. Table (2)

Comparison between the mean values of the marginal adaptation of the specimens with digital and conventional impression was used. $\mathrm{T}$ test analysis showed a significant difference between the mean values in the buccal side (Digital image) $79.9 \pm 5.34$ and the mean values in buccal side of the conventional impression $84.6 \pm 4.72$ Table (3) and Figure (1).

Comparison between the mean values of the marginal adaptation of the specimens with digital and conventional impression was used. $T$ test analysis showed a significant difference between the mean values in the lingual side (Digital image) $77.1 \pm 5.93$ and the mean values in lingual side of the conventional impression 84.4 \pm 5.82 Table (3) and Figure (1) 
TABLE (1): Comparison between vertical marginal adaptation in buccal and lingual(digital impressions). (T tests) The group (A).

\begin{tabular}{|c|c|c|}
\hline Digital impression & Buccal & Lingual \\
\hline Min & 72 & 70 \\
\hline Max & 87 & 86 \\
\hline Mean & 79.9 & 77.1 \\
\hline \pm SD & 5.34 & 5.93 \\
\hline T & 1.115 & \\
P & 0.294 & \\
\hline
\end{tabular}

TABLE (2): Comparison between vertical marginal adaptation in buccal and lingual conventional impressions). The group (B).

\begin{tabular}{|c|c|c|}
\hline Conventional impression & Buccal & Lingual \\
\hline Min & 77 & 77 \\
\hline Max & 90 & 92 \\
\hline Mean & 84.6 & 84.4 \\
\hline \pm SD & 4.72 & 5.82 \\
\hline T & \multicolumn{2}{|c|}{0.103} \\
P & \multicolumn{2}{|c}{0.920} \\
\hline
\end{tabular}

Table (3): Shows the means and standard deviations of vertical marginal discrepancies in each group.

\begin{tabular}{|c|c|c|}
\hline Digital impression & Buccal & Lingual \\
\hline Min & 72 & 70 \\
\hline Max & 87 & 86 \\
\hline Mean & 79.9 & 77.1 \\
\hline Conventional impression & \multicolumn{2}{|c|}{77} \\
\hline Min & \multicolumn{2}{|c|}{77} \\
\hline Max & 90 & 92 \\
\hline Mean & 84.6 & 84.4 \\
\hline \pm SD & 4.72 & 5.82 \\
\hline $\mathrm{T}$ & 3.66 & 2.567 \\
$\mathrm{P}$ & $0.005^{*}$ & $0.030^{*}$ \\
\hline
\end{tabular}

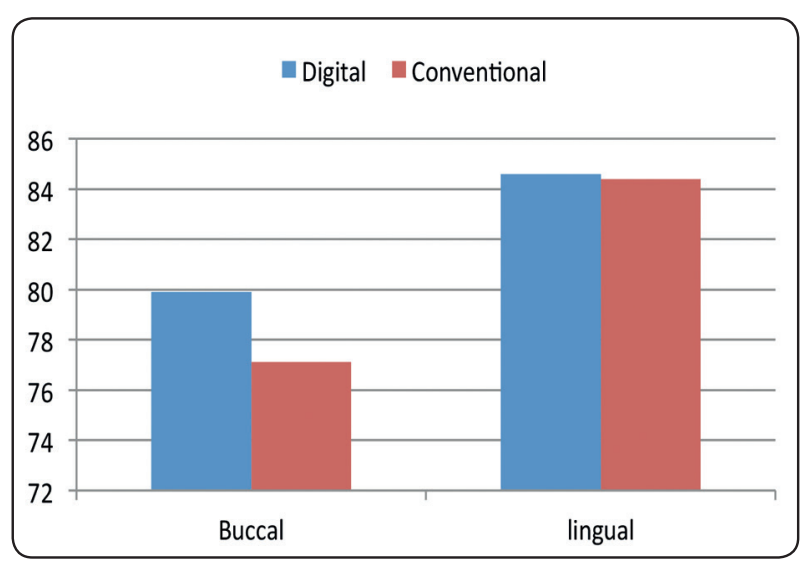

Fig. (1): Bar chart representing the marginal adaptation in both groups.

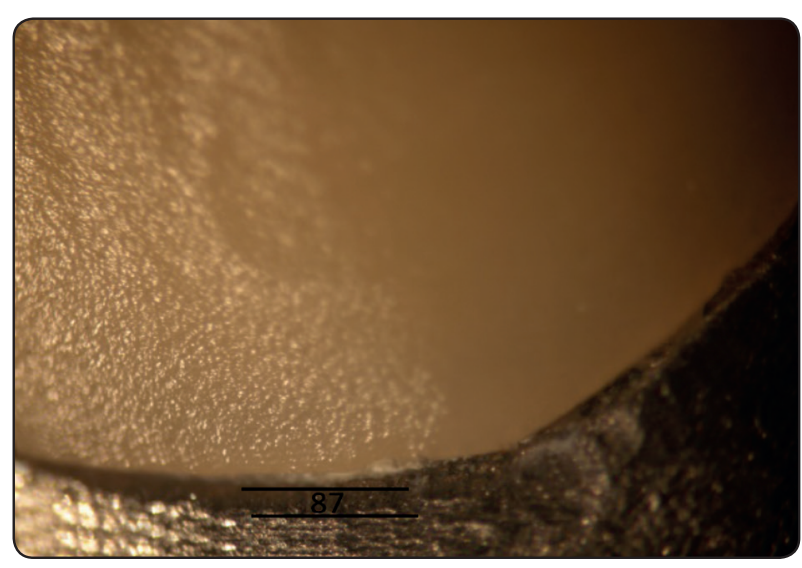

Digital impression technique buccal view

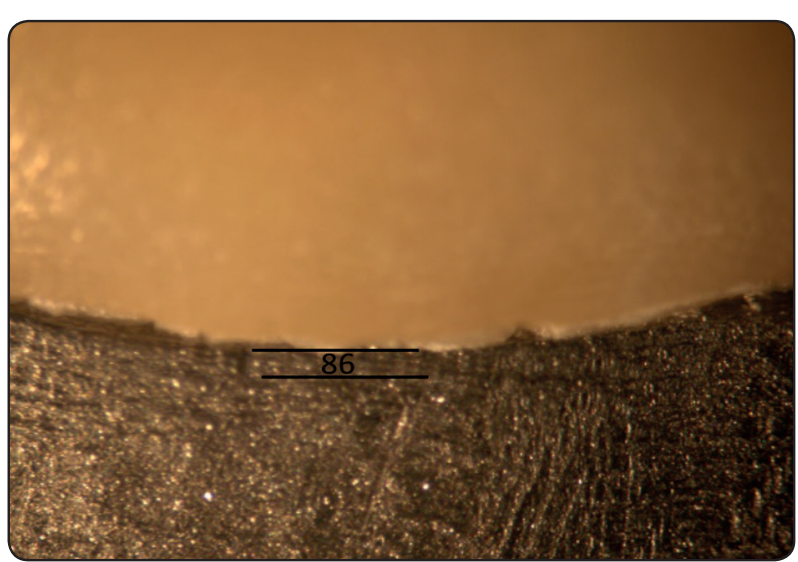

Digital impression technique lingual view 


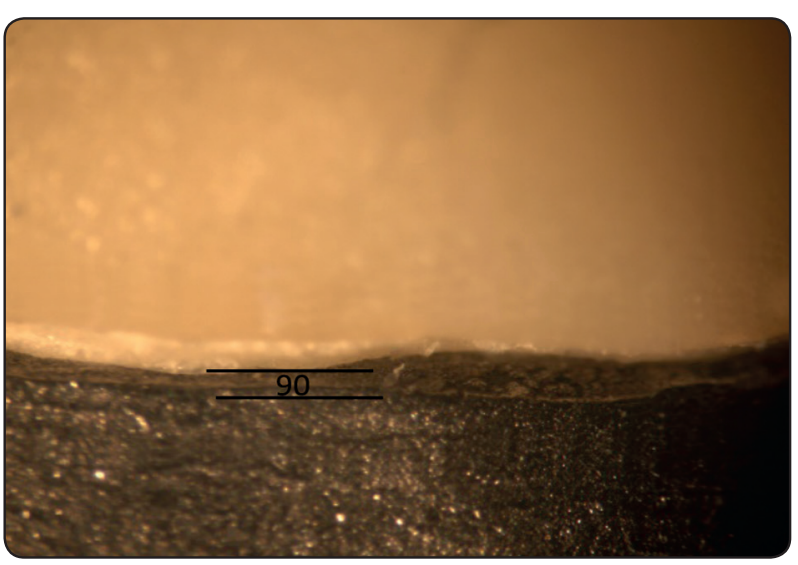

Conventional impression technique buccal view

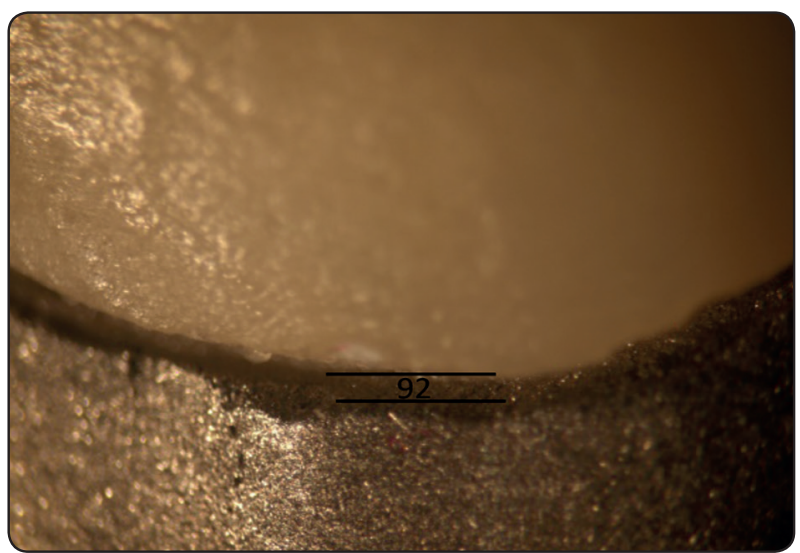

Conventional impression technique lingual view

\section{DISCUSSION}

This study compared the vertical marginal discrepancies (distances between prepared margin and restoration margin) of crowns manufactured by CAD CAM and laboratory technique using two different impression techniques. The first is digital image and the second is conventional impression. A stereo microscope $\mathrm{x} 50$ has been used to measure the external marginal gaps.

Three common techniques were reported in the literature to measure the marginal gap, the first technique is the measurement of sectioned specimens, the second technique is the impression replica technique of the marginal gap, and the third is the direct view of the external marginal gaps of the crown on a die.$^{(14,15,16)}$
Good adaptation has been found to be critical for the longevity of a crown. Poor marginal fit can lead to caries, micro-leakage, and dissolution of cement. $^{(17,18)}$

As marginal fit ${ }^{(19,20)}$ plays such an important role in the clinical outcome of a crown, it is important to determine whether or not CAD/CAM crowns are acceptable alternative to laboratory processed crowns. ${ }^{(21,22,23,24)}$

The marginal adaptation in this study was determined as a linear distance from the external margin of all-ceramic crown and the finish line of the preparation.

The present study reveals that the marginal gap is significantly higher for IPS e-max press fabricated by conventional impression and laboratory technique compared to digital impression technique and CAD CAM crowns. This may be attributed to the accuracy of digital image compared to conventional impression techniques and also could result from the multiple laboratory fabrication steps.

The results of the present study was in agreement with the study of Syrek et al, ${ }^{(25)}$ where crowns fabricated with Lava COS and conventional impressions were compared.

Lava crowns had a statistically significant smaller marginal gap size compared with the conventional group.

Another study was conducted by Ting-Shu Su, and Jian Sun found that the marginal and internal fit of frameworks fabricated from the intraoral digital impression system were better than those fabricated from conventional impressions. ${ }^{(26)}$

Studies in literature have shown that clinically acceptable marginal gap size is less than $120 \mathrm{~mm}$. However, there is no consensus on the maximum clinically acceptable marginal gap size. A wide range of values has been reported in the literature. ${ }^{(26)}$ 
Christensen found, that an acceptable gingival margin range is $34-119 \mu \mathrm{m} .{ }^{(27,28)}$

McLean and von Faunhofer, also, suggested that restorations with marginal gap less $120 \mu \mathrm{m}$ are more likely to be successful. ${ }^{(29)}$

Some studies have found $<120 \mu \mathrm{m}$ acceptable, while others previous studies have found that marginal discrepancies in the range of $40-160 \mu \mathrm{m}$ accepted. ${ }^{(30)}$

The difference in values may be attributed to lack of standardization in measurement methodology, making comparison among studies a challenge.

In this study the mean marginal adaptation were found to be within the range of accepted finding in the literature.

Many studies compared marginal gap of a laboratory made crowns and CAD/CAM crowns, both were found to meet the clinically acceptable level. ${ }^{(31)}$

Yeo et al, reported that the marginal openings of In-Ceram and IPS Empress 2 crowns were 112 and $46 \mathrm{~mm}$, respectively, which is in agreement with the results of this study. ${ }^{(32)}$ Sulaiman et al evaluated the marginal gap of In-Ceram crowns and found it to be $160.66 \mathrm{~mm}$. Those results are also in accordance with this study. ${ }^{(33)}$

A review was made by Chochlidakis $\mathrm{KM}$ et al to compare marginal and internal fit of fixed dental restorations fabricated with digital techniques to those fabricated using conventional impression techniques concluded that the digital impression technique provided better marginal and internal fit of fixed restorations than conventional techniques did which coincide with this study. ${ }^{(34)}$

An in vitro study by Abdel-Azim $\mathrm{T}$ et al compare the marginal gap discrepancy of lithium disilicate single crowns fabricated with $\mathrm{CAD} /$ CAM technology by using both conventional and digital impression techniques and concluded that digital and conventional impressions were found to produce crowns with similar marginal accuracy, this study is not in agreement with this study may be because the variation in techniques and materials. ${ }^{(35)}$

Beyari $\mathrm{M}$ in his study reported that all-ceramic crowns produced using the chair side CAD/CAM system had in vitro marginal fits that were not significantly different than marginal fits of all-ceramic crowns produced by dental laboratories. The difference in measuring parameters and techniques may cause the difference in the results of this study. ${ }^{(11)}$

Another study by $\mathrm{Ng} \mathrm{J}$. et al reported that the digital impression technique provided better marginal and internal fit of fixed restorations than conventional techniques did. ${ }^{(10)}$

While there is a conflict in literature in comparing laboratory processed ceramics to $\mathrm{CAD} / \mathrm{CAM}$ ceramic crowns but the majority are supporting the finding of clinically acceptable marginal fit of CAD/ CAM restorations of various types. ${ }^{(36)}$

The results of this study support that the marginal fit of all ceramic crowns fabricated by digital image technique are better than that fabricated by conventional impression technique.

\section{CONCLUSION}

Within the limitations of this study, all-ceramic crowns produced by digital techniques (CAD/CAM) had vertical marginal adaptation accuracy better than all-ceramic crowns produced by conventional impression techniques with statistical significant difference.

\section{REFERANCES}

1. Conrad HJ, Seong WJ, Pesun IJ. Current ceramic materials and systems with clinical recommendations: a systematic review. J Prosthet Dent 2007;98:389-404.

2. Mathieu Contrepois et al, Marginal adaptation of ceramic crowns: A systematic review. J Prosthet Dent 2013;110:447-454

3. Lee KB, Park CW, Kim KH, Kwon TY. Marginal and internal fit of all-ceramic crowns fabricated with two different CAD/CAM systems. Dent Mater J 2008;27:422-6. 
4. Beuer F, Edelhoff D, Gernet W, Naumann M. Effect of preparation angles on the precision of zirconia crown copings fabricated by CAD/CAM system. Dent Mater J 2008;27: 814-20.

5. Miyazaki T, Hotta Y, Kunii J, Kuriyama S, Tamaki Y. A review of dental CAD/CAM: current status and future perspectives from 20 years of experience.Dent Mater J 2009;28:44-56.

6. Luthardt, R.G., Bornemann, G., Lemelson, S., Walter, M.H., Huls, A. An innovative method for evaluation of the 3-D internal fit of CAD/CAM crowns fabricated after direct optical versus indirect laser scan digitizing. The International Journal of Prosthodontics.2004; 17(6):680-5.

7- Mohammed M. Beyari .Marginal and Internal Crown Fit Evaluation of CAD/CAM versus Press-Laboratory AllCeramic Crown. Clinical Medicine and Diagnostics 2014, 4: 21-26.

8- Ting-Shu S, Jian S. Intraoral digital impression technique: a review. J Prosthodont 2015;24:313-21.

9- Rekow ED. Dental CAD/CAM systems: a 20-year success story. J Am Dent Assoc 2006;137:55-65.

10- Ng J, Ruse D, Wyatt C. A comparison of the marginal fit of crowns fabricated with digital and conventional methods. J Prosthet Dent 2014;112:555-60.

11- Sepulveda-Rodríguez, A., Guerrero-Martínez, F., GaitanFonseca, C., Komabayashi, T., Reyes-Vela, E.and Masuoka, D. Evaluation of the marginal adaptation in metal crowns using CAD/CAM and manual wax patterns.Microscopy Research, 2015; 3:26-32.

12- Bindl, A., Mormann, W.H., Marginal and internal fit of allceramic CAD/CAM crown-copings on chamfer preparations. Journal of Oral Rehabilitation 2005, 32(6):441-7.

13- Mohammed M. Beyari . Marginal and Internal Crown Fit Evaluation of CAD/CAM versus Press-Laboratory AllCeramic Crown. Clinical Medicine and Diagnostics 2014, 4: $21-26$

14- Munir Tolga Yucel et al. In vitro evaluation of the marginal fit of different all-ceramic crowns. Journal of Dental Sciences $2013: 8: 225-230$.

15- Balkaya M, Cinar A, and Pamuk S. Influence of firing cycles on the margin distortion of 3 all-ceramic crown systems. J Prosthet Dent 2005; 93:346-55.

16- Ushiwata $\mathrm{O}$, and Vieira DE, and Moraes J, Method for marginal measurements of restorations:Accessory device for Toolmakers microscope.J Prosthet Dent 2000;83:362-6.
17- Tsitrou E, Northeast S, and Noort R. Evaluation of the marginal fit of three margin designs of resin composite crowns using CAD/CAM. J Dent 2007; 35:68 -73.

18- Mirza Rustum Baig et al. Evaluation of the marginal fit of a zirconia ceramic computer-aided machined (CAM) crown system. J Prosthet Dent 2010;104:216-227.

19- Hisham A. Mouslyet al. Marginal and internal adaptation of ceramic crown restorations fabricated with CAD/CAM technology and the heat-press technique. J Prosthet Dent 2014;112:249-256.

20- Beuera F, Aggstallera H, Edelhoffa D, GernetaW, and Sorensenb J. Marginal and internal fits of fixed dental prostheses zirconia retainers. Dent Mater 2009; 25: 94-102.

21- Andradea O, Goesa M, and Montesb M. Marginal adaptation and microtensile bond strength of composite indirect restorations bonded to dentin treated with adhesive and low-viscosity composite. Dent Mater 2007; 23: 279-287.

22- Kokubo Y, Ohkubo C, Tsumita M, Miyashita A, Vult von Steyern P,Fukushima S. Clinical marginal and internal gaps of Procera AllCeram crowns. J Oral Rehabil 2005;32:52630 .

23- Jacobs MS, Windeler AS. An investigation of dental luting cement solubility as a function of the marginal gap. J Prosthet Dent 1991;65:436-42.

24-Beschnidt SM, Strub JR. Evaluation of the marginal accuracy of different allceramic crown systems after simulation in the artificial mouth. J Oral Rehabil 1999;26:582-93.

25- Syrek A, Reich G, Ranftl D, Klein C, Cerny B, Brodesser J. Clinical evaluation of all-ceramic crowns fabricated from intraoral digital impressions based on the principle of active wavefront sampling. J Dent 2010;38:553-9.

26- Ting-Shu Su, and Jian Sun, Comparison of marginal and internal fit of 3-unit ceramic fixed dental prostheses made with either a conventional or digital impression J Prosthet Dent 2016; ;116:184-90.

27- Holmes JR, Bayne SC, Holland GA, Sulik WD. Considerations in measurement of marginal fit. J Prosthet Dent 1989;62:405-8.

28- Christensen GJ. Marginal fit of gold inlay castings. J Prosthet Dent. $1966 ; 16(2): 297-305$.

29- McLean JW, von Fraunhofer JA. The estimation of cement film thickness by an in vivo technique. Br Dent J. 1971;131(3):107-11. 
30- Coli P, Karlsson S. Fit of a new pressure sintered zirconium dioxide coping. Int J Prosthodont 2004;17:59-64.

31- Tinschert J, Natt G, Mautsch W, Speikermann H, Anusavice KJ. Marginal fit of alumina- and zirconia-based fixed partial dentures produced by a CAD/CAM system. Oper Dent 2001;26:367-74.

32- Yeo IS, Yang JH, Lee JB. In vitro marginal fit of three allceramic crown systems. J Prosthet Dent 2003;90:459-64.

33- Sulaiman F, Chai J, Jameson LM, Wozniak WT. A comparison of the marginal fit of In-Ceram, IPS Empress and Procera crowns. Int J Prosthodont 1997;10:478-84.
34- Chochlidakis KM, Papaspyridakos P, Geminiani A, Chen CJ, Feng IJ, Ercoli CJ. Digital versus conventional impressions for fixed prosthodontics: A systematic review and meta-analysis Prosthet Dent 2016 ;116(2):184-190.

35- Abdel-Azim T, Rogers K, Elathamna E, Zandinejad A, Metz M, Morton D. Comparison of the marginal fit of lithium disilicate crowns fabricated with CAD/CAM technology by using conventional impressions and two intraoral digital scanners. J Prosthet Dent. 2015;114(4):554-9.

36- Reich, S., Gozdowski, S., Trentzsch, L., Frankenberger, R., Lohbauer, U., Marginal fit of heat-pressed vs. CAD/ CAM processed all-ceramic onlays using a milling unit prototype. Operative Dentistry 2008;33(6):644-50. 